\section{EFFECT OF OIL ON DISTURBED WATER.}

GENERALLY speaking, proverbs are the resultant $G$ expression of observed facts, but the efficacy of oil upon troubled waters would appear to be a proverb which, instead of being preceded by and founded upon trial and experiment, has rather led to the scientific demonstration and establishment of the truth it asserts. From the very earliest ages the effect of oil when poured upon disturbed water appears to have been widely known. Aristotle mentions it, and accounts for the phenomenon by assuming that the thin film of oleaginous matter into which oil resolves itself when poured upon water prevents the wind from obtaining a hold upon the water, and so checks the wave formations which are the usual results of wind at sea. Pliny, too, observes that among the officers of his fleet the soothing influence of oil was matter of common knowledge, and that the Assyrian divers were in the habit of sprinkling the surface water with oil when they wished to smooth down ripples, and so obtain a better light for prosecuting their work below. Coming down to more recent times, the custom of oiling the waves with a view to facilitate navigation would appear to have fallen into desuetude. Benjamin Franklin, however, seems to have been led, from observing the effect of pouring overboard some greasy water, to test its potency in a thoroughly scientific manner, when on a voyage across the Atlantic. Having experimented with great success upon the surface of a pond near London, he tested the effects of oil upon the sea itself. stormy day was chosen, and from a boat, some half a mile from the beach at Portsmouth, oil was poured upon the sea. The experiment met with a very small share of success, for, while a greasy patch of water was discernible right to the shore, the surf continued to break upon the beach with unabated vigour. Subsequent and recent investigation has confirmed Franklin's finding, and proved that the greatest benefit derived from the use of oil is obtainable in deep water, where wave-motion is merely undulatory. When a shoreapproaching wave ceases to find enough depth to impart to its neighbour its peculiar undulatory motion, it is no longer a wave pure and simple, but becomes an actual moving body of water which moves rapidly forward, until it breaks with great violence upon the shore; upon such waves as these, oil has little or no effect.

The knowledge of the influence of oil upon a rough sea has long been known to those engaged in the whale and seal fisheries, and its application is of common occurrence. When their vessels or boats are overtaken by a storm, they usually, by means of a drogue or sea anchor, make what is nautically termed a dead drift, i.c. they suffer themselves to be slowly drifted before the wind. In such circumstances as these, the application of oil to the waves insures that the area into which the boat drifts is one of calm, as the oil spreads more rapidly than the boat moves, and consequently prepares a smooth patch for the vessel to drift into. If the captain, however, prefers to run his vessel before the wind, then she ranges ahead of the oiled patch, and thus the effect of oiling the waves is very materially discounted.

The native Eskimo, when engaged in transporting his family from place to place, always insures a smooth passage for the oomiak, or women's boat, by trailing a punctured skin filled with oil from the stern of his kayak, which he propels at some considerable distance ahead of the boat containing his wife and children.

Within the last twenty years many well-authenticated instances have been placed on record as to the potency of oil as a water-soother, but unfortunately the value of such reports is very much diminished by the ship-masters neglecting to explain the relative position of their vessel in regard to the wind and sea. The British warship Swiftsure, when on a voyage from Honolulu to Esqui- mault, encountered a gale accompanied by tremendous seas. A bag, punctured with the point of a knife, was filled with oil and rigged out on the weather side of the vessel. This had such a marked effect, that the vessel rode bravely through the gale, and reached her destination in perfect safety. On October 8, 1880, a Mr. Fondacaro left Monte Video for Naples in a three-ton boat. He arrived at Malaga on February 4, I88I. On his voyage across the Atlantic, he had repeatedly to lay-to during stress of weather, and reports that he considered his safe arrival entirely due to his use of oil. A gallon of olive-oil would last him, when hove-to, for twenty-four hours. He gives it as his experience that oil does not diminish the size of the waves, but renders them comparatively harmless by preventing their breaking. There is a consensus of opinion among those who have tested the use of oil, that a small quantity is quite as efficacious as a larger one, a consumption of one pint per hour being sufficient. Small as this quantity is, the extreme expansibility of oil when floating upon the water renders it quite adequate. Thus a ship running ro knots an hour will leave behind her a wake some ro knots by 40 feet, covered with a thin film of oil.

The Dunkirk Chamber of Commerce, fully alive to the vast importance of the use of oil as materially conducing to safe navigation, have just reported on the results of some tests made at their direction among the French fishing fleet off Iceland. One master reports that by its use he was enabled to ride out successfully a prolonged and severe spell of bad weather, which compelled his confrères to run to port until the weather moderated. The Chamber rewarded him with roo francs. Other captains who have reported in detail the result of their experiments, agree with him in stating that, for small vessels experiencing stress of weather in deep water, the use of oil cannot be too highly recommended.

Nor is the utility of oil confined alone to this branch of marine navigation. Advices just received from New York furnish some interesting particulars relative to the towage of the disabled steamship Italia of the Hamburg American Company. The Italia broke her shaft whilst proceeding from Havre to New York. In this condition she was taken in tow by the Gellert, of the same company. The towing hawsers-6-inch steel wirewere lengthened by heavy chain cables until the distance between the two vessels was increased to rooo feet. Unfortunately, a heavy gale from the north-west caused a dangerous sea to arise, and it was feared that the Italia would have to be abandoned. As a last resort, a can of oil with a small hole in the bottom was set over the stern of the Gellert. The effect, according to the master, Captain Kampf, was magical. The seas broke over the bows of the Italia with much less fury, merely surging past in a heavy swell, while the tension on the cable was immediately relieved, and the Gellert was enabled, in spite of continued bad weather, to reach New York in safety, having towed her charge continuously for the distance of 750 miles. Possibly many cases of abandoned towages in bad weather might be averted did the masters of tugs but try the effect of a little oil prior to casting the vessel adrift.

The true part played by this oleaginous film in diminishing the disturbance of the sea seems to be that of a lubricant. Waves are formed by the friction of wind and water. Any force, therefore, that tends to lessen the friction reduces the violence of the waves. As far as is at present known, animal or the heavier vegetable oils form the best lubricant between the two elements. Mineral or fossil oils, which possess less viscosity and are less oleaginous in their mechanical properties, exert much less influence upon the water. This anti-frictional force of oil can hardly be over-estimated. The Atlantic waves have been calculated to exert an average pressure 
during the winter months of 2086 pounds per square foot. During a heavy gale this pressure is increased to 6983 pounds ; yet the thin oil blanket is sufficient, when applied under certain conditions, to enable a vessel to navigate through them in perfect safety, their oiled summits raising themselves in sullen grandeur, but never breaking aboard. What the exact coefficient of friction between air in motion and water is, and the proportion of its reduction by oil or other lubricants, are questions that open up a most interesting subject of inquiry, the resolution of which will prove highly beneficial to the whole nautical and mercantile world.

Numerous experiments have been made with a view to testing the utility of oil in smoothing the approaches to exposed harbours in rough weather. The tests undertaken at Peterhead have met with unqualified success. The modus operandi has been to lay leaden pipes along the bottom of the harbour, taking care to keep the pipes stationary by means of concrete. The pipe is provided with numerous roses for disseminating the oil. When rough weather comes on, oil is forced along the pipes, and it escapes into the water through the apertures provided, and then, its specific gravity being less than that of water, it rises to the surface and quickly renders the sea less turbulent and the passage into the harbour quite safe. Another method employed to render safe ingress into harbours in bad weather is that of firing out to sea an oil-carrying projectile. This consists of a heavy tin tube weighted with lead at one end. The tube is filled with two or three quarts of oil, and the aperture stopped. When the projectile is fired from a gun or mortar, it reverses, and, the time-fuse exploding, the powder blows out the plug, and the liberated oil falls into the sea. A series of experiments, conducted by a Committee appointed by the United States Life-saving Service to inquire into the practical utility of oil-carrying projectiles, goes to confirm the statement made above, viz. that the power of oil to subdue the force of the waves in shoal water, or to prevent the waves breaking in surf, is very small indeed. There is one point, however, upon which all authorities who have tested the use of oil at sea are agreed. As an adjunct to the equipment of ships boats it is simply invaluable. Many a shipwrecked crew have been enabled to keep their frail craft afloat until land was reached or a rescue effected, solely by its use. Nothing is more common among the records of shipwrecks than to read of the small boats either being swamped while at the vessel's side, or capsizing through stress of weather. In January 1884 the Cambria emigrant ship was run into by the Sultan in the North Sea, and, out of 522 on board, 416 were drowned. Of the four starboard boats, no less than three capsized, and all their occupants perished. In the collision in the Channel between the Forest and Avalanche, two out of three boats which left the Forest were swamped, and all on board lost their lives. These are but two instances out of many where lives might have been saved by the use of a little oil.

The subject of saving endangered life at sea is one that always enlists the deepest sympathies of all sorts and conditions of men. The perusal of the "Annual Wreck Chart," published by the Board of Trade, or of the lamentable records of personal sorrows and destitution consequent upon the disasters around our coasts, suggests the possibility that the loss of life might be considerably reduced by a practical knowledge of the best methods of applying oil during storms at sea. We think that much might be done by its use to facilitate the launching of boats from distressed vessels, and their safe subsequent navigation. Harbours of refuge on exposed coasts might be established at a very small cost.

In one department alone of our maritime industry, deep-sea fishing, many lives might be saved. At present, the mortality among the carriers, i.e. those engaged in carrying in small boats the fish from the smacks to the steam despatch-boats, is very great. Their boats might be equipped, at a very low cost, with oil-tanks or oil-bags to be used when trans-shipments are being effected in heavy weather. Already the Governments of the United States and Germany have realized the vast importance of this subject, and have instituted an exhaustive series of experiments with the view of rendering compulsory the carrying of oil for use as a life-saving equipment. When that complex and overburdened instrument of government, the Board of Trade, was asked in Parliament to cause experiments to be made relative to the use of oil at sea, the reply was, that there were no funds available for the purpose ; that the Board could not spend money or become investors in such schemes. The Consultative Committee appointed under the Life-saving Appliances Act of last year have, however, suggested oil-bags, among other equipments, to be carried by boats and rafts. At the International Maritime Conference at Washington, U.S., this subject has received the attention its importance merits. Further, the National Life-boat Institution and the National Sea Fisheries Protection Association have amalgamated their forces with a view to testing the efficacy of oil, but as yet the results of their investigations have not been published. While it is very gratifying to know that the man of science and the philanthropist are ready to explore the practical utility of this question, we cannot hope for any satisfying material results until the Board of Trade sees its way to take administrative action in the matter, and to deal in a fitting manner with a question that is so indissolubly connected with the interests of all classes of this great mercantile community. RICHARD BEYNON.

\section{RECENT OBSERVATIONS OF JUPITER.}

0 BSERVATIONS of Jupiter have been conducted under great difficulties during the past opposition in consequence of the low altitude of the planet. His elevation, even at meridian passage, has only been about $16^{\circ}$, as observed in this country, so that the study of his surface markings has been much interrupted by the bad definition which usually affects objects not far removed from the haze and vapours on the horizon. It is, however, important that planetary features, especially those which exhibit changes of form and motion, should be watched as persistently as circumstances allow, and with this purpose in view Jupiter has been submitted to telescopic scrutiny whenever the atmosphere offered facilities for such work during the past summer and autumn. Few opportunities occurred, however, during the latter season owing to the great prevalence of clouds, and on the several nights sufficiently clear for the purpose, the atmosphere was unsteady and the definition indifferent; thus the more delicate lineaments of the planet's surface could be rarely observed with satisfactory distinctness.

The great red spot was visible on the night of May 21 , I889, and it was estimated to be on the central meridian at $\mathrm{I} 2 \mathrm{~h}$. $3 \mathrm{Im}$. Further views of the same object were secured in June, July, and later months. In appearance and form it presented much the same aspect as in preceding years. Its elliptical outline is still preserved, and there seems to have occurred no perceptible change in its size. It is somewhat faint relatively to the very conspicuous belts north of it, and it is only on a good night that it can be well recognized as a complete ellipse with a dusky interior. On the evening of September 12 last, I obtained an excellent view of it with my Io-inch reflector, power 252. The spot was central at $6 \mathrm{~h} .33 \mathrm{~m}$., and its following end was seen to be much the darkest. This has usually been the case, and I have often noticed a very small, black spot at this extremity. Another observation was effected on the early evening of November 26, when the spot crossed the planet's centre at $3 \mathrm{~h}$. $54 \mathrm{~m}$., but the 